A paper presented at the 26th annual convention of

the American Institute of Electrical Engineers,

Frontenac, N. Y. June 28, 1909.

Copyright 1909 . By A.I.E.E.
(Subject to final revision for the Transactions.)

\title{
CENTRALIZATION OF POWER SUPPLY
}

President's Address

BY LOUIS A. FERGUSON

The most prominent characteristic of present-day industrial development is the tendency to consolidate. It is so apparent on every hand that this may well be called the Age of Centralization. The economies that may be effected by large production and centralized direction are being appreciated more and more, and extremely large industries have been, and are being, built up by combining many individual plants. In the main, such combinations have resulted in material benefits to the country and its people.

The lessened cost of wholesale manufacture permits a lower selling price, thus placing the commodity within easier reach of a larger number. The greater economy of production resulting from manufacture in large quantities and with improved methods is and will continue increasingly to be a material factor in that very important problem of the conservation of resources, which is so prominently before this and other countries at the present time.

In the industry of electric power production the advantages of centralization seem thus far to have failed somewhat of full appreciation, but the awakening is apparently at hand. In a few noteworthy instances centralization was planned and put into effect some years ago, and the work already done will blaze the way for others. When the economies of concentrated management and large production are more generally understood the growth of centralization will be rapid.

From whatever standpoint we view the problem the advantages stand out boldly. The investor will be more favorably impressed 
with large issues of securities which require no detailed information. These securities will be easily marketed and on much more favorable terms than is possible with the smaller issues of individual companies. Large as this saving is, by far the most important one results from the economies effected by combined investment and output. The load-factor of our central stations; that is, the ratio of the average load to the maximum load, absolutely controls the earning capacity of the investment. The cost of generating and distributing electricity consists primarily of fixed charges on the investment and of operating costs. The fixed charges are independent of the hours use of the equipment; therefore, if the load continues heavy for long hours daily the fixed charges are distributed over a larger output and the cost per unit of output is thereby lessened. In other words, with long hours use a greater output follows, and greater earnings are produced without any increase in the investment. Obviously, therefore, the greater the proportion the fixed charges bear to the total cost the greater will be the effect of the load-factor. In modern large power systems, as in water-power plants, the operating costs are now so low that they represent a comparatively small part of the total costs, the fixed charges constituting by far the larger part. The importance of a good load-factor is thus apparent and everything that will improve this factor should be sought.

The yearly load-factor for any one class of service is determined largely by the seasons, the habits of the people, and similar conditions which ordinarily do not change. Improvement in loadfactor must therefore be obtained largely by combining different classes of service, the maximum demands of which occur at different times of the day or of the year. Also, the larger the number of customers in any class the better will be the load-factor.

The ratio between the sum of the maximum demands of various classes of service to the actual simultaneous maximum demand is termed the diversity factor, and the more non-coincident peak service that is combined in one system the greater will be this factor. It is here that centralization presents its mosit marked effect in increasing the load-factor and thereby the economy of production. The addition to a central station system of business having a high load-factor, such as power business for all-the-year-round service, amusement parks, auto charging and refrigeration for the summer, utilizing the otherwise idle investment, is desirable not only in itself but also because it reduces the cost of the entire output. 
The whole community through this reduction in cost is thus benefited by centralization, since the central station company is enabled to sell its product at a lower price to the small consumer because of the improved condition of manufacture effected through the supply of its product to the large consumer.

In the power station the larger output of combined loads will permit the use of large generating units which have a high performance efficiency, and which require a comparatively small operating force. This results in further reduction of costs. The investment per kilowatt, not only for the apparatus but for the land and building as well, is also less for large units, and the total reserve required by the centralized system will be but a small fraction of the combined reserve required where the load is furnished from individual systems. The saving in investment in this single item of reserve alone is an important factor in the problem. One of the leading causes for the success which has attended the development of the electrical industry in this country has been the standardization of equipment, and the American Institute of Electrical Engineers has been the active leader in this important work. It is still a far cry to the ideal but all steps taken should be in the forward direction. Centralization leads toward standardization. In the present state of the art, generation will be by three-phase alternating current and the predominating demand will determine the frequency, be it 25 or 60 cycles or some other frequency. If, however, the demand in any community for an auxilliary standard frequency becomes sufficiently large even though it remain a small part of the total output, then generation at this auxiliary frequency is justified; but connecting links of ample capacity should be provided between the sets of generators of different frequency so that the advantages of the diversity factor and of common reserve may still obtain. The voltage should also be so chosen that the transmission cable may be interchangeable between the two systems.

An incidental advantage of centralization, which, however, is of great sociologic importance in a community, is the resultant cleanliness due to the absence of countless smoking chimneys. This fact is being actively recognized by civic improvement bodies and such recognition is a valuable asset to a central station company in the prosecution of its industrial power campaign.

One of the early and prominent examples of centralization is found in England where the Newcastle-upon-Tyne Electric 
Supply Company furnishes energy to one of the most important manufacturing areas in the United Kingdom. A special effort has here been made to develop particularly the industrial power business and the general adoption of electricity has had a marked effect on the industrial conditions in that district. The tramways are operated from this system as well as electrified steam roads. In many of the smelting mills the waste gases are used to produce steam in boilers and the energy thus derived is used in turbine stations and is fed into the general system, the same smelting mills being in turn customers of the supply company. The total load is not so very large compared with that in some of our American cities, but this system is mentioned in such detail because it typifies what can be done in the way of centralization. There is still a good deal of independently produced power in the district, but it will undoubtedly eventually be won over by the supply company. Even though the difference in efficiency between the smaller turbine units and the larger units is decreasing, the diversity factor will in most cases enable the supply company to underbid independent producers.

The diversity factor is the very foundation rock of centralized energy supply. It is the birthright of the central station, the fundamental reason for its existence and its resultant value belongs to the central station company.

In some American cities, as already stated, the total load is considerably greater than in the example just cited, but the centralization possibilities are only just beginning to be developed.

The system of the Pacific Gas \& Electric Company with its hundreds of miles of transmission lines, its many customers among the mines dotting the hills, and the many cities receiving electrical power from the company, is perhaps the nearest approach to the Newcastle system. At Niagara the transmission lines are reaching out in all directions and we may hope to see one of the great industrial centers of the future in that locality. At the present time there are many independent companies, and the full benefits of centralization will not be realized until the stations are loaded up to the point where they will be compelled to arrange for interchange of energy.

Chicago, because of its strategical location regarding transportation, is certain to remain one of the world's greatest markets and industrial centers. If the imagination were allowed full play the possibilities in power requirements of the future in the Chicago districts would appear almost boundless. A vigorous 
start toward centralization of power production has already been made. Street-railway power houses have been shut down and the energy for the operation of the street railways is purchased in whole or in part from the central station company.

The supply of power for electrified steam railways is one of the possibilities of the near future and engineering plans and expenditures of past years have been made with a view of taking care of wholesale industrial business on a comprehensive scale.

In a large number of cities two prominent public servicesstreet railways and electric lighting-were originally inaugurated by one company, and with the natural growth and development of the two systems the electrical generation has in many cases been unified so that one set of generators furnishes energy for both railway and lighting. However, in most of these cities the industrial power business has not been vigorously developed either because of lack of appreciation of its value or timidity on the part of the supply company in making sufficiently low prices to obtain the business.

There are also very few, if any, communities or territories in which the centralization of power supply for all purposes has been effected and in which electric power is utilized in such manner that the best economic results are realized. By combining all systems of neighboring cities within a radius of 30 or 40 miles into a single centralized system a great saving in production would result and in most cases an improvement in service as well. The utilization of water powers will help in this direction.

The monopolistic character of the electric power industry is now being recognized by the intelligent public and monopoly privileges with proper regulation are being granted as the best safeguard for the interests of the people. The legal way is thus being paved for the beginning of centralization. Such centralization will naturally include the power for electrified steam railways, the universal coming of which is but a matter of time. In most instances the total amount of power required by a railroad for its terminal and suburban service, even where counted in the tens of thousands of kilowatts, is but a small part of the total power required for all purposes within the same area.

If this railway power is generated in a separate plant the loadfactor would be far below that of the central station and the necessary reserve capacity would require a high fixed charge to be carried by the plant. With less reserve the reliability of the service might suffer disastrously. No railroad could thus generate its 
own power as cheaply or as securely as it may be purchased from a properly directed central station company. This applies also and to an even greater extent to power production for industrial uses or to individual generation for any purpose.

In cities where the power production is not centralized, a multiplicity of systems of voltages and often of frequencies is usually found, and the duplication which spells waste is abundant.

Without the economies resulting from centralization the price of the output will necessarily remain higher than otherwise and the community must pay the cost. With the lower efficiency of generation the fuel resources are wasted and the entire country will ultimately suffer as a result.

It has seemed to me that a condition of such transcendent importance to the electrical profession should receive liberal attention and consideration from our Institute. We, as an organization, have a large part to play in the development of the art of electrical application as well as in electrical science.

There is scarcely any branch of the electrical industry which does not ultimately affect or which is not in a measure affected by this development.

The progressive work of the electrical engineer will determine with what success we can reach out into these larger fields. The mechanical engineer has given us a steam turbine of greatly improved economy; it is for us to improve still more the method of transmission and conversion and the application of electricity in the arts. High-voltage transmission made possible our entry into this field, but, while very great advances have been made, there are still some unsolved problems in this field and particularly with regard to underground transmission. There are also many problems and countless opportunities in connection with the utilization of electrical energy. The successful solution of these problems is of the utmost importance.

It is for the commercial electrical engineer (which really includes nearly all of us) to educate the layman and particularly the power user to an appreciation of the superiority and desirability of electric service and to emphasize the material and ethical advantages to a community of centralized power production.

It is for the technical electrical engineer to furnish him with the sinews of war, with the ammunition to conquer in the fields where waste, where useless dissipation of energy prevails. We should bend every effort to advance the cause of centralization with its resultant economic gains. Those connected with the 
manufacturing interests especially should not tolerate for an instant a selfish backward step within their fold.

As we meet here in convention to gain a broader knowledge and to discuss important problems let us think of these opportunities which our profession affords in this grand movement for world betterment, this guiding of the forces so that Nature's bounty to man will bring to him the highest and greatest good. The thought carries with it inspiration and enthusiasm and a determination to do our part, individually and collectively, in the successful upbuilding of an industry which means so much to the economic development of the country's resources.

Some day, in the centuries yet unborn, the broadening perspective of time will show more clearly the full significance of these days' accomplishments. Surely, gentlemen, nothing could be more inspiring to greater effort than the knowledge that we have in our hands the means for this achievement. 